\title{
The Rapidly Disappearing Science and Art of Pathology in Developing Countries
}

\author{
Dr. Raghvendra Gumashta ${ }^{1}$, Dr. Shamim Akhtar ${ }^{2}$ \\ ${ }^{1}$ Department of Community Medicine, ${ }^{2}$ Department of Pathology, N. K. P. Salve Institute of Medical Sciences \\ $\&$ Research Centre, Nagpur.
}

\begin{abstract}
The carefully learnt and traditionally transferred art and science of observation, precision and distinguished unparalleled competence is diminishing its glory into the dark horizons through its disintegration in multiple new disciplines, high technological advancements and non-sustenance with the pace of rapid scientific growth. Such a scenario is resulting into general disinterest of medical graduates into the discipline of Pathology, low morale of its practitioners and near absolute termination of opportunities to grow among the subject experts.

A loud thinking is necessitated among the medical fraternity, in general, and pathologists, in particular, to device the ways and means of rejuvenating the ever rusting status of Pathology. This shall not only enable enthusiasm among its practitioners, but also generate new ventures for innovations, education and research. The article highlights the intrinsic and extrinsic, but closely interwoven factors, situations and circumstances, which if dealt with great care shall yield rich dividends towards reverting the current trend, develop future models of growth and sustainability in the field of Pathology.
\end{abstract}

Key Words: clinical, diagnosis, laboratory, pathological, qualitative, testing

\section{Introduction}

A pathologic diagnosis is the result of a complex series of activities, mastered by the pathologist. The nature of these activities is, however, rarely talked about in depth. The medical literature occasionally discusses aspects of the pathologic diagnosis processes, generally departing from the pathologic practice. The process of diagnosis can be viewed as an action plan, encompassing four domains of cognitive, communicative, normative, and medical conduct. The cognitive domain involves processes of perception, attention, memory, search, hypothesis creation, and verification, among others. Communicative skills consist of providing arguments in support of a diagnostic conclusion, with adequate clinical and relevant pathologic information. Pathologic diagnosis is also subject to technical rules (based on empirical experiences), rules of rational choice (strategies aiming at definite goals), and consensual rules among peers. ${ }^{[1]}$ Pathology services represent the rational, scientific basis of the practice of clinical care. It does not represent deus ex machina, an implausible solution to a complex plot, but rather the way in which clinical care can be audited, controlled, guided and kept appropriate to the funds and the skills available. ${ }^{[2]}$ Effective utilization of clinical laboratories requires that underutilization, overutilization, and mal-utilization be appreciated and eliminated or reduced ${ }^{[3]} \mathrm{New}$ and expensive treatments, introduction of difficult to interpret complex tests, a greater reliance on nurse practitioners as deliverers of primary care and patient initiated testing, all make it likely that in the future greater emphasis will be placed on appropriate use of cost-effective laboratory tests. The most promising solution to inappropriate utilization of laboratory services is a greater reliance on clinical laboratory consultants. At present, many laboratory physicians and scientists cannot compete with specialist physicians in terms of the ability to provide credible helpful advice on test selection and results interpretation. ${ }^{[4]}$ Hence, there is need to study the intrinsically interwoven complex framework of Pathology, its strengths, weaknesses, opportunities and threats, so as to assess the future of rapidly disappearing science and art of Pathology over the vast horizons of medical sciences.

\section{Material \& Method}

An exhaustive review of available information on the concerns of Pathology discipline and the pathologists in general, was obtained through opinion seeking from stakeholders. An academic qualitative study of the current status of science of Pathology with special reference to the generally observed scenario in government and private tertiary health care institutions of developing countries was also done, while interviewing persons in the field and using Google search engine on internet, for assessing the short term and long term survival of science of Pathology in view of fast technological advancements \& ground realities.

\section{Result \& Discussion}

The areas of focus in this study have been on administration, co-ordination, external \& internal quality adherence, output assurance, expansion of services, upgrading of the equipments, competitive survival with 
private health care providers, training \& refresher capacity building initiatives, development of new tools \& methods, monitoring \& evaluation of services and research related challenges. This study also concentrates on the analysis of these issues according to the horizontal and vertical integration as well as inter-disciplinary aspects.

\section{Utility Vs Threats}

Laboratories are complex work-places with secretarial and administrative, as well as analytical, functions. ${ }^{[5]}$ The discipline of pathology has been successful in changing the clinical diagnosis in its true perspective in the interest of proactive patient care. Thus, the role of Pathology is immense but it needs strengthening from all perspectives.

Although the clear cut demarcation of Pathology being a dependant branch is visible in foreign countries, but progression towards such a scenario is not very far in developing countries since the independence of this branch is being carried away by the outstanding contribution of its modern branches, which have gone so far that those seem to be separate entities and also do not recognize their subject of origin to a great extent. In addition, the proponents of Pathology put forth the argument that no branch of medical sciences is devoid of its thrust and thirst to reach the highest horizons of excellence and therefore visibility of such a phenomenon in Pathology cannot and should not be termed as something unusual or a matter of anxious moments.

The upgrading of the existing equipments and changing the outdated equipments is linked generally to the naturally expected monetary, quantitative and qualitative returns of the provisions and services expected through such change and hence needs technical \& reasoned institutional developmental presentations associated with determined efforts and personal follow up. Such efforts, if done in the above said succession, generally yield positive results. However, delay in carrying out such tasks may have adverse impact on enrichment or capacity building of the departmental outputs, which, irrespective of the intrinsic limitation (if any), are expected to perform parallel to the best in the tertiary health care system in the country and sometimes compared with world class facilities. Therefore, development of a systematic and systems based approach for pre planned and expected qualitative outputs need to be devised, so as to have recommendatory notes generated through the software thus developed. The fulfillment of the long desired change after sustained demands by the patients or circumstances creates enabling environment towards the early investments based on the recommendations of the interdepartmental consultation committee or through other similar initiatives.

The field of Pathology, like any other discipline of public health services, is not untouched by the VIP (Very Important Person) syndrome, wherein out of turn, immediate or high priority attention is given to the politically, socially and economically powerful persons thereby delaying the reporting of the others. This phenomenon is generally seen almost equally among government, semi-government and private sector based health care services.

Although the panels of sera/samples of Haematology, Biochemistry, Histopathology and Fluid/ Serum are obtained \& tested with utmost sincerity of the purpose and speed in compliance to the apex laboratory's instructions, the desired purpose may be partially defeated in view of testing being done for overloaded sample sizes \& types due to ever increasing influx of self motivated or hospital services popularity \& reliability based referred indoor and outdoor patients. This definitely puts enormous pressure on the performance quality of the pathologist since the focus on time bound performance targets naturally corners one towards undesired compromises for the quality outputs, innovations or desirability for researching the new found observations for peculiar or particular chance/purposive findings due to lack of time, resources and energy on the part of the individual and the department. Being technically vigilant, resourceful and attentive towards fulfilling the expectations of the patients is the one of the best options.

The healthy system of adhering to the hierarchy of opinion seeking practices, in either of the disputed, rare or circumstantial cases, may be avoided due to the work pressure generated loss of academic interest, expressed or apparently invisible but existing personality clashes and unfulfilled dreams of personal achievements due to known or unknown, valid or invalid reasons. Therefore, existence and observations of the best practices documents and standard operative procedures are necessitated at each and every level of quality assurance.

\section{Teaching \& Experience}

The importance of undergraduate and graduate medical education in laboratory medicine to insure understanding as well as effective utilization is stressed. ${ }^{[3]}$ Although the meetings and academic discussions held by Association of Pathologists \& Microbiologists are held regularly and CME (Continuing Medical Education), UG-PG (Undergraduate-Postgraduate) Quiz, Seminar, Conferences, Outreach Programs are also organized, the undergraduate medical teaching in the medical colleges and other teaching institutions require strengthening towards ensuring adequate emphasis on optimal use of the new teaching methodologies including exhaustive use of black board teaching, power point based teaching, video clips, animation lecture series, hands on training and other useful time tested techniques of developed countries.

Attention is focused on the specialty context as a key factor in influencing the development of clinical management. It also suggests there may be other important factors, for example: training; the role of change 
agents; structure of clinical directorates; and individual factors such as cognition, attitudes and motivation. ${ }^{[6]}$ Educational prerequisites to effective consultation are: understanding of disease pathogenesis, knowledge of clinical problem solving and identification with clinical questions. The latter requires clinical experience or intensive training in clinical laboratory consultation. Further barriers to implementation of comprehensive laboratory consultation services include resistance on the part of practicing physicians, health care administrators and insurers. Whether these barriers can be overcome or not, the future will include comprehensive laboratory consultation services conducted through web-based access to advice on test selection and interpretation of results. ${ }^{[4]}$

Table I: Transitioned branches of Pathology

\begin{tabular}{|l|l|l|l|}
\hline No. & $\begin{array}{l}\text { Branch of Pathology in } \\
\text { tertiary health care } \\
\text { services }\end{array}$ & $\begin{array}{l}\text { Now renamed and } \\
\text { transitioned as }\end{array}$ & Impact on Pathology \\
\hline 1 & Blood Banking & $\begin{array}{l}\text { Blood Transfusion } \\
\text { Medicine }\end{array}$ & $\begin{array}{l}\text { Lost authority and control on blood } \\
\text { banking system }\end{array}$ \\
\hline 2 & Dermato-pathology & $\begin{array}{l}\text { Branch } \\
\text { Dermatology }\end{array}$ & $\begin{array}{l}\text { Overworked scheduling and convenience } \\
\text { of procedures has shifted attention of } \\
\text { Pathology from this field. }\end{array}$ \\
\hline 3 & Serum Testing Lab & Immunology & $\begin{array}{l}\text { National Premier Institutes and other } \\
\text { experts in the field have gone miles } \\
\text { forward in Immunology. }\end{array}$ \\
\hline 4 & Biochem Lab & Biochemistry & $\begin{array}{l}\text { Bio-chemisty has now become a very } \\
\text { different and distinguished field. }\end{array}$ \\
\hline 5 & Autopsy Reports & Forensic Science Lab & $\begin{array}{l}\text { Specialized laboratories of forensic } \\
\text { science have minimized seeking services } \\
\text { of Pathology. }\end{array}$ \\
\hline 6 & Bacteriology Section & Microbiology & $\begin{array}{l}\text { This recent phenomenon has gained fast } \\
\text { momentum for its establishment, identity } \\
\text { and purpose. }\end{array}$ \\
\hline 7 & Histopathology & Molecular Biology & $\begin{array}{l}\text { Rapid up-gradation and advancement is } \\
\text { leading to the science of 21 century, the } \\
\text { Molecular Biology. }\end{array}$ \\
\hline 8 & Branch Experts & New Subject Experts & $\begin{array}{l}\text { Branch Experts were aware of other } \\
\text { branches, but new subject expert generally } \\
\text { only conversant with their own branch. }\end{array}$ \\
\hline 9 & Speciality & $\begin{array}{l}\text { Not keeping pace with time has resulted in } \\
\text { fast fragmentation of Pathology }\end{array}$ \\
\hline
\end{tabular}

\section{Research}

The scattered and mostly unnoticed initiatives of few pathologists in various branches of pathology like developing a new reagent, new diagnostic method or using material available in the laboratory as replacement part(s) for costly imported machines to run successfully require sharing of these experiences and expertise on the wider platforms for their replicable use by others in the field.

Increased research and development, an active managerial role on the part of pathologists, internal selfassessment, and an aggressive response to sophisticated scientific and clinical laboratory data base requirements are not only desirable but essential. ${ }^{[3]}$ The participation in National \& International workshops or conferences in the field of Pathology is done in passive manner by the Pathologists because of their busy schedule, non compulsion of participation or due to their physical absence associated negative impact on the performance of their service facility. There are experts of undisputed excellence in the field of Pathology and allied branches, however they need to streamline their resources for fast dissemination of the achievements made, researches done and expression of desired changes in the practice \& performance of the discipline in accordance with the present day requirements, clinical, ethical and medical practice norms.

It is not so that the pathologists are not organizing their subject specific workshops at local levels. These are observed regularly in the fields of Haematology, Histopathology and Karyotyping with sufficiently representative participation. The pathologists do participate in the CMEs or Conferences, generally only when its very convenient to attend, highly informative or driven by compulsions of peer pressure. There is much room for individualized and collective efforts for striving towards excellence, while associating all concerned including the requisitioning doctor, the pathologist $\&$ his team of technicians and the beneficiaries. However, 
their active participation with indigenous developmetal initiatives shall yield rich dividends in terms of diagnosing the emerging and re-emerging infectious diseases in developing countries.

The inclination, as observed, towards serious scientific research is not as per the learned faculties available in this science and therefore much needed enthusiasm among the long neglected scientists of pathology, generally known as pathologists, requires drastic changes in the philosophy, psychology and practice orientation; all targeted and directed towards attention for the people's welfare through inventions of new diagnostic facilities, new ways of cost effective approaches and re-defined professional service catalogue.

\section{Government Sector Vs. Private Sector}

Optimal patient care service, although subjective to a major extent, is reflected in terms of outcome and cost. Increased per diem charges, reduced hospital stay, and increased laboratory workload over the past decade all require each laboratory to examine its internal operations to achieve economy and efficiency as well as maximal effectiveness. ${ }^{[3]}$ The government funded facilities do receive support as per the annual plan, contingency plans \& under various funding support mechanisms including foreign grants and assistance, especially for research and development purposes; whereas, the private sector based facilities service enhancement is generally based for fulfillment of the devised requirements, profitability of the equipment as per the cost benefit analysis and user friendly nature of the machine. The non-beneficial services viz. special tests, hormonal assays, immuno-histochemistry) are, however, taken care of by outsourcing these services to the external service provider on no profit no loss basis.

Not as a rule, but a common finding has been there that the government sector based tertiary health care facilities in the field of Pathology are excelling in infrastructure and manpower support base, however, their counterparts in the private sector are focusing on the quality, administrative issues like timeliness, completeness and purposiveness of the reports while having testing machines which are definitely at par or advanced on comparative terms with many of the premier institutions of developing countries.

Although the private medical colleges are, in many of the circumstances, at par with the national institutes of excellence but the lack of sustained exposure, oration skills, presentation skills and confidence of clinical diagnosis are some of the factors which are reasoned to be the causes of lagging behind of such private medical institutions. The proactive efforts for national accreditation viz. NAAC (National Assessment \& Accreditation Council) accreditation or international accreditation like WHO (World Health Organization), United Nations Agency accreditation are desired, however generally not sought after. Irrespective of the type of the sector, the institution's willingness to get associated or becoming linked with 'National or International Centers of Excellence' depends on the individual interests, collective wisdom based initiatives or the institutional academic environment.

Table II: Examples of pathologist's interpretations for improvements in clinical decision making

\begin{tabular}{|c|c|c|c|c|}
\hline $\begin{array}{l}\text { S } \\
\text { No }\end{array}$ & $\begin{array}{l}\text { Clinical } \\
\text { Discipline }\end{array}$ & Clinical Diagnosis & $\begin{array}{ll}\text { Identified } & \text { by } \\
\text { Pathologist as } & \\
\end{array}$ & Result \\
\hline 1 & Medicine & Anemia & Leukaemia & \multirow{11}{*}{$\begin{array}{c}\text { Evidence } \\
\text { based decision } \\
\text { making } \\
\text { resulting in } \\
\text { better clinical } \\
\text { course }\end{array}$} \\
\hline 2 & Medicine & Malignancy & $\begin{array}{l}\text { Leishmaniasis (Kala } \\
\text { Azar) }\end{array}$ & \\
\hline 3 & Medicine & $\begin{array}{c}\text { Coma due to } \\
\text { Haemorrhagic Viral } \\
\text { Encephalitis }\end{array}$ & Uraemic Coma & \\
\hline 4 & Paediatric & Haemoglobinopathy & Malaria & \\
\hline 5 & Skin & White Patches & Leprosy & \\
\hline 6 & Skin & Paniculitis & Psoriasis & \\
\hline 7 & Skin & Leprosy & Xanthoma & \\
\hline 8 & Surgery & Pancreatic Cyst & Malignancy & \\
\hline 9 & Surgery & Nasal Malignancy & Fungal Infection & \\
\hline 10 & Surgery & Lipoma & Sarcomatous Lesion & \\
\hline 11 & Surgery & Dermoid Tumor & Endometriosis & \\
\hline
\end{tabular}

\section{Constraints Induced Performance Crisis}

The constraints being faced by pathologists of all sectors include lack of finances, trained manpower and expertise trainings at national or international institutes (viz. for immuno-histochemistry, molecular biology etc.) including less offers for exchange programs and availability of quality full text reference materials from around the world.

Most clinical laboratories report severe difficulties in recruitment and retention of most types of personnel. Other important factors impacting this problem include work complexities, increased automation, and 
The Rapidly Disappearing Science And Art Of Pathology In Developing Countries

a graying workforce. As a further challenge, institutional needs for clinical laboratory personnel are expected to grow significantly in the next decade. Laboratory Managers need to become transformational leaders by developing effective staffing models, fostering healthy and productive work environments, and creating value with a strategic management culture and implementation of knowledge management. ${ }^{[7]}$ Cost accounting is one such management practice: costs are analysed into a number of elements and these are recombined in various ways according to the purpose to be served. Such a purpose might be selection of an operating procedure, control of expenditure, or the setting of prices for the product. ${ }^{[5]}$

There are episodes of emergencies as performance output crisis when the technicians do leave their entrusted job all of a sudden mostly due to better job offers from elsewhere, under high stress of overburdened responsibilities \& answerabilities, improper work load distribution among working technicians and other unknown incomprehensible reasons, as observed in developing countries. As a solution to such problems, for instance in cases of strike, emergencies or sudden overload due to public health emergencies of disproportionate dimensions, the trained staff of departments of Physiology, Forensic Medicine and Biochemistry are deputed to assist. Such workable measures are essentially required for global, especially in developing world, management of the resource crunch in any field, especially in the fields of subject expertise.

\section{Output \& Quality Enhancement}

An analysis, based on a range of archived and interview data collected over the period 1997-2000, suggested that publicly unacceptable compromises in pathology service quality were risked by the pursuit of tight bureaucratic and free market controls over pathology practice. ${ }^{[8]}$ However, the proponents of careful purchase decision making state that its ideal to commence procurement of equipments on reagent rental basis initially for new equipments and thereafter an evidence based decision should be taken in accordance with the patient load, handling convenience and reliability of the results. This shall serve the dual purpose of pre-testing of machine for purchase agreement $\&$ on-site training of the personnel for gaining confidence and assessing the base requirements.

Participation in a local audit scheme can offer more direct benefits than those which may be achieved by participation in a diagnosis based external quality assurance system, but the two are not incompatible ${ }^{[9]}$ In partial fulfillment of such a scenario, it has been an, many a times observed, issue of concern that although the results of haematology are compulsorily counter checked, those of biochemistry may not be counter checked; whereas the histopathology samples are taken care of with great precautions and in doubtful, unclear or dubious samples, the tradition of seeking senior opinion, outside opinion or submitting it as a discussion case is religiously practiced. In the latter case(s), a consensus decision is arrived at, after exhaustive due deliberations of multi departmental discussions in the clinical meetings, for continuing the ongoing case management or conducting advanced investigations of microbiological or other nature.

The costs and limitations as well as the accuracy, precision, sensitivity, specificity, and pitfalls of measurements and examinations must also be fully appreciated. ${ }^{[3]}$ There is need to add organizational diagnostic instruments and theory, concerned with such phenomena as accountability and authority, organization structures, talent pool development processes, personal effectiveness appraisal and merit review, differential compensation, and level of work measurement. ${ }^{[10]}$ Internal Quality Controls are although exercised with military precision of competence through use of commercially prepared standards, pooled serum testing, cross checking with other practitioners on mutual understanding, running the manually checked test sample on fully automated machines, performing validity test every week for adjusting the validifying factor of the automated machine or comparing with the known case results; however, there are many unaddressed opportunities for internal quality control initiatives like developing exclusive compulsory and listed controls at all the levels of testing, re-testing, comparing and opinion seeking.

One study revealed that in pathology there is a major dependency on quality control that reflects a compliance to set standards laid down by professional bodies. It also identified a poor understanding of customer needs and expectations, a mechanistic culture which is resistant to change, and a reluctance by pathology managers to delegate ownership for ongoing quality improvement or to take responsibility for quality improvement issues such as waste reduction and cost improvement. ${ }^{[11]}$ The development of internal control mechanisms by the peer groups for bringing an end to the observed, however not common, unacceptable and professionally unethical practices especially in private service provider individuals shall help to minimize the quality deterioration and bring back the honor of subject among colleagues. The silence of honest peers should not be taken for a ride while compromising with the Hippocratic Oath undertaken by one and all in the profession.

\section{Innovations}

The rotational postings of pathologists in Out Patient Department, Indoor Health Facilities, Testing Laboratories, Pathology Department, Inter-departmental tasks and clinical committee meetings do not complete the exhaustive list of generally entrusted tasks and he/she is also entrusted as an expert in the purchase 
committees, instrument maintenance committees, development committees, up-gradation committees, quality assurance committees and technical committees and hence he/she is performing tasks of three days in one day. The obvious results are seen as overburdened pathologist with short term sickness absenteeism or stress induced non communicable disease(s).

\section{Recommendations}

The recommendations based on the inference drawn are as follows:

1. There is dearth of research, training and development of indigenous technology in the field of Pathology in developing countries.

2. Strict compartmentalization of the discipline has led to its untimely slow death.

3. The disintegration of discipline of Pathology into 'Microbiology', 'Bio-chemistry', 'Forensic Medicine' and now 'Molecular Biology' has posed threats for the existence and recognition of Pathology as independent science.

4. Non medicos are posing threats to the survival of subject experts. It's a very pitiable situation and needs immediate attention \& necessary measures, as deemed correct and fit by the associations of pathologists.

5. Pre analytical and analytical parts are being taken care of by DMLT (Diploma in Medical Laboratory Technicians), whereas the post analytical part is being taken care of by the equally or higher competent experts of newly developed but now remotely \& weakly linked branches of Pathology viz. Microbiology, Molecular Biology, Genetics etc.

6. The disinterest of medical graduates may mar the prospects of development of Pathology and will therefore create a vacuum of subject experts in future. Such conditions of technical inconclusiveness due to lack of subject experts in discipline of Pathology may further be aggravated by delayed, incomplete or incoherent results of the tests from various deeply segregated quarters of dissociating new branches of Pathology.

7. The only ray of hope for survival of the discipline of Pathology is the strong link of Pathology with Primary Health Care Facilities through government, semi-government and private service providers since the newly developed branches viz. 'Molecular Pathology' will require much time to reach such remotely located service destinations or it may, in future, be part of the modernized, as expected by the mid-century, primary health care service delivery system.

\section{Conclusion}

The Pathologists of long drawn experiences tell us, although without any grudges, that a day will come when the morphological study of histopathology and cytology will totally depend on the study of molecular biology along with full automation of the results. Probably there shall be no scope of Pathology and the need of undergoing undergraduate or postgraduate medical courses may not remain as compulsion to perform and excel in its new found branches. The circumstances themselves shall delete the demand of Pathologists and graduate/post-graduates of Biotechnology may be better suited to the upcoming competitive environment, if no noticeable changes are taken up. But, at the same time they state that the future is unpredictable and hence nobody knows whether the lost glory of Pathology shall be regained or not. The stalwart of Pathology need to take the survival of this science as challenge and focus on the excellence of inputs in terms of performance, research and new initiatives.

The high quality task performances done by the pathologists against multitude challenges, especially by the high output public service facilities, requires much sought after appreciation and adequate attention by the varied stakeholders including funding agencies, program managers and local experts. It shall boost their capacities in terms of re-energizing them for taking initiatives in the interest of poor, downtrodden and weaker sections of the society thereby serving the true purpose of their expertise.

\section{References}

Pena G P, Andrade-Filho J S, How Does a Pathologist Make a Diagnosis?, Arch of Path \& Lab Med 2009; 133(1):124-132.

Gray I P, Carter J Y. An evaluation of clinical laboratory services in sub-saharan Africa: Ex africa semper aliquid novi?, Clinica Chimica Acta 1997; 267(1):103-128.

Murphy J, Henry J B. Effective utilization of clinical laboratories, Hum Patho 1978; 9(6): 625-633.

[4] Burke M D. Clinical laboratory consultation: appropriateness to laboratory medicine, Clinica Chimica Acta 2003; 333(2): 125-129.

[5] Barclay J E, Special problems of cost analysis and cost-benefit analysis as applied to large multi-test analysers, J of Autom Chem 1983; 5, (2):71-74.

[6] Willcocks S. The development of clinical management at an NHS Trust hospital: A case study example, J of Mgt in Med 1994; 12(3):168-177.

[7] Ward C, Kendal, Ramirez, Bernardo, Rotarius, Timothy. The Laboratory Workforce Shortage: A Managerial Perspective, Hea Care Mgr 2011; 30(2):148-155.

France N, Lawrence S, Smith J F. New Zealand pathologists: a case study in occupational control, J Mgt in Med 2001, 15(1):28-43. Ramsay A D, Locally organised medical audit in histopathology, J Clin Pathol 1991;44:353-357.

Jaques, Elliott. Diagnosing sources of managerial leadership problems for research and treatment, Consult Psych J: Pract \& Res 2001; 53(2): 67-75.

[11] Feeney A R, Zairi M. Best Practice Quality Management in Pathology: Results of a Benchmarking Study, Qual Mgt \& Tech 1994; 1(2): 64-80. 